\title{
Institutional and Financial Aspects of Implementation of the Concept of State-Private Partnership at the Federal and Regional Levels
}

\author{
Natalya Nikolaevna Novoselova ${ }^{1}$ \\ Madina Valentinovna Alikaeva² \\ Madina Batyrovna Ksanayeva² \\ Tatyana Aleksandrovna Nalchadzi ${ }^{2}$ \\ Lidiya Zalim-Geriyevna Kerefova² \\ ${ }^{1}$ North Caucasian federal university \\ 2Kabardino-Balkarian state university of H.M. Berbekov Russian Federation; Email: nnn-nauka@yandex.ru
}

Doi:10.5901/mjss.2015.v6n5s3p338

\section{Abstract}

\begin{abstract}
In article the stages of modernization of the state support of small and average business concept representing a vector of its development are developed and offered. One of the most significant factors of a small business development is the system of the taxation. The main directions of improvement and further development of the special tax modes are considered: 1) fixing of concept «subjects of MSP in the Russian Tax Code; 2) reduction of application conditions of the special tax modes and conditions of reference of the enterprises to small and to average to the uniform standard; 3) introduction of an ascending scale of a unified tax - from $5 \%$ to $15 \%$ for the simplified tax system; 4) establishment of opportunity to accept to a deduction the entrance VAT at the subsequent realization of goods «uproshchenets» to the VAT organizations payers; 5) introduction of the concept "conscientious taxpayer» and a ban of carrying out exit checks of such taxpayers - micro and small enterprises. Results of research can promote expansion of theoretical, methodological and practical base of the state support of development of small and medium business.
\end{abstract}

Keywords: financial mechanism, small and average business, state support, conscientious taxpayer, entrance VAT.

\section{Introduction}

Process of system `s modernization of the state support of small and average business (further - MSP) assumes its evolutionary updating on essentially new theoretical basis, namely - on the basis of the system approach applied within the institutional theory (Alikayeva, 2006). It means development of the new concept of the state support of MSP. The new concept consists in development of sector of small and average business through improvement of institutes of its state support. Institutes are understood as set, both infrastructures of state support of MSP, and institutional (formal and informal) the rules providing its functioning (Vilensky, 2006, p. 45). Use of different instruments of support for different groups of subjects of MSP is important for implementation of the new concept: average, small and micro (Alikayeva, 2014, p. 67).

The support infrastructure of MSP in the legislation of the Russian Federation is understood as system of the organizations (commercial and noncommercial) created and which are carrying out the activity or attracted as suppliers, performers or contractors at placement of state orders at implementation of federal and regional programs of development of MSP. The infrastructure of support of MSP includes:

- agencies and the centers of development of MT;

- funds of assistance to crediting and supports of small enterprises;

- investment funds (joint-stock and closed);

- scientific and technical parks;

- the innovative centers and supports of a subcontract;

- business incubators;

- $\quad$ the marketing centers; 
- educational business centers;

- agencies on support of export of goods;

- the leasing companies;

- advice centers and other organizations (The act of the Russian Federation of 24.07.2007 № 209-FZ).

\section{Main Part}

The following institutes (The law KBR of 24.04.2007 № 29-RZ) present the infrastructure of support of small and average business of the region now:

- Parliament of KBR (regulatory authority of the territorial subject of the Russian Federation);

- Council for business at the President of KBR (coordination council);

- The ministry of economic development of KBR, the Government of KBR, the Ministry of information communications, work with public associations and to affairs of youth of KBR, the Ministry of Finance of KBR (executive authorities of territorial subjects of the Russian Federation);

- 13 municipal funds of support of small business of KBR (on areas and city districts of the republic);

- Guarantee Fund KBR non-profit organization;

- GU «Kabardino-Balkarian Business Incubator», HEY «Business-incubator of the Baksan municipal area», «The Business Incubator Administration».

- Consumer cooperatives (27 organizations).

The main normative legitimate acts, composing the institutional basis of q small business activity in Russian Federation are: The federal law № 209 «About state support of MSP», the Tax code of the Russian Federation (part 1 and 2), regional laws on state support adopted on the basis of SL-209, the antitrust law and some other (The tax Code of the Russian Federation (part second) of 05.08.2000 № 177-FZ; The act of the Russian Federation of 24.07.2007 № 209FZ; The act of the Russian Federation of 26.07.2006 № 135-FZ \& The law KBR of 24.04.2007 № 29-RZ).

Measures for existing system of state support improvement are formulated on the bases of SWOT analysis of state support system of MT on macro - and meso-levels, estimates of its advantages and weaknesses (table 1).

Table 1 - SWOT-analys of system of state support of MSP

\begin{tabular}{|c|c|}
\hline $\begin{array}{l}\text { Macro-level: } \\
\text { 1. Existence of the Law on state support of MT } \\
\text { (Federal Law № 209) } \\
\text { 2. Introduction of the special tax modes, decrease in } \\
\text { tax burden of subjects of MT } \\
\text { 3. A wide range of measures for support of MT } \\
\text { provided by SL-209 } \\
\text { 4. Growth of number of subjects of MT } \\
\text { Meso-level: } \\
\text { 1. Existence of the special regional Law on support } \\
\text { of MT } \\
\text { 2. Wide range of measures for support of MT in the } \\
\text { regional Law on support of MSP } \\
\text { 3. Active participation the MAYOR of KBR in support } \\
\text { 4. Competitions business of ideas, grants } \\
\text { 5. Existence of various programs of training } \\
\text { 6. Opening of a network of business incubators in } \\
\text { the region } \\
\text { 7. Edition of brochures, distribution of information on } \\
\text { state support measures to mass media }\end{array}$ & $\begin{array}{l}\text { Weaknesses } \\
\text { Macro-level: } \\
\text { 1. Lack of economic definition of sector in SL-209 } \\
\text { 2. Inaccessibility of the special modes to the small and average organizations, discrepancy of } \\
\text { criteria in the Tax Code and SL-209 } \\
\text { 3. Limitation of instruments of support in practice } \\
\text { 4. Decrease in the main indicators of development counting on } 1 \text { enterprise (number of workers, } \\
\text { commodity turnover, etc.), absolute domination of the microenterprises } \\
\text { 5. Growth of payments on social insurance for individual entrepreneurs } \\
\text { Meso-level: } \\
\text { 1. Lack of economic definition of sector in the regional Law } \\
\text { 2. Lack of the mechanism of the concrete mechanism of rendering state support of MSP } \\
\text { 3. Not development of concrete procedures of rendering advisory support } \\
\text { 4. Subjectivity of decision-making, opacity of carrying out competitions, imperfection of selection } \\
\text { criteria of projects, lack of possibility of online control of carrying out competitions, poor quality of } \\
\text { business projects, lack of high-quality market researches } \\
\text { 5. Low economic efficiency of programs, lack of innovations and introduction of the gained } \\
\text { knowledge and skills at the small enterprises } \\
\text { 6. Granting production and office rooms for only the first } 3 \text { years of activity of the organizations, } \\
\text { nonflexible lease term, impossibility of their use for the organizations undergoing temporary } \\
\text { financial difficulties } \\
\text { 7. Untimely informing, inefficient submission of information, limitation of direct contacts of } \\
\text { representatives of state agencies with the population on rendering state support } \\
\text { Threats } \\
\text { Bankruptcy of the most part of the created enterprises } \\
\text { Degradation of the existing enterprises } \\
\text { Reduction of number of individual entrepreneurs } \\
\text { Partial transition of MSP activity into the semi-legal state (further - «Shadowing») } \\
\text { Deterioration of structure of sector of MSP }\end{array}$ \\
\hline
\end{tabular}

Source: Author's development 
So according to the table 1, advantages of state support system of MSP are now:

1) macro-level - creation of the new law on state support, involvement in system of state support of a wide range of the enterprises, development of a wide tool kit of its rendering in the Law on state support, the special tax modes for subjects of MSP, growth of number of MSP subjects;

2) meso-level - creation of the regional law on state support of MSP, active speed up the MAR of KBR in support, carrying out competitions, training programs, granting grants, opening of business incubators.

Despite the available advantages, the system of state support of MSP is not without serious shortcomings.

1. At macro-level:

- imperfection of definition of sector of MSP and criteria of classification of the enterprises in the law on state support;

- inaccessibility of the special tax modes to medium-sized and small enterprises;

- high tax burden, growth of payments on obligatory social insurance;

- a tendency to crushing of the enterprises and a «Shadowing» of their activity;

- decrease in the main indicators of their development;

- absence of incentives for businessmen to business expansion;

- vulnerability of the public expenditures on support of small business.

2. At micro-level:

- lack of the mechanism of rendering financial support;

- lack of an operating control behind realization and achievement of goals and problems of state support of MT;

- weak level of knowledge of small businessmen of opportunities of receiving the state help;

- lack of high-quality monitoring of activity of small enterprises;

- lack of feedback; in some cases duplication of functions and emergence of «white spots» in system of state support of small enterprises;

- complication of the accounting and reporting for small enterprises, opacity of decision-making in the sphere of rendering financial state support of MSP.

The new concept consists in development of sector of small business through modernization of system of the state support of this sector and represents the purposeful program including rigid sequence of interdependent and interdependent stages (figure 1).

Elaboration of the definition of the small business
Improvement of the enterprises definition criteria as "micro" and "small"
Optimization of the state support system
Enhancement of the state financial and credit support mechanism

Figure 1 - Concept of development of system of state support of MT.

The purpose of this system in a general view consists in ensuring sustainable dynamic development of small business in regions of the Russian Federation.

According to the model given above the first stage of improvement of the concept of the state support of small business is elaboration of the definition of the small business. Formation of effective system of the state support of small sector demands revision of approaches to definition of essence of the term «small business» taking into account its economic and institutional components. It will allow preventing abuses and unfair competition of the enterprises having a dominant position in the local regional markets, and replacement from them small firms (Vilensky, 2006).

The following stage of the concept's implementation - improvement of the enterprises definition criteria as "micro" and "small". It will allow to achieve bigger qualitative uniformity of structure of these groups and to provide them equal access in the competition for receiving the state support. Dimension of the subject of the enterprise environment causes types and forms of his state support (Alikayeva, 2006). 
Basis for construction and justification of quantitative limit values of reference of the enterprises to micro, small or to average is the analysis of qualitative differences of these groups and the existing system of criteria that allows formulating measures for their improvement.

Criteria of small business, in turn, cause measures of the state support of small business. Therefore, revision of criteria of small business inevitably conducts to need of improvement of tools of its state support.

One of the most significant factors of development of small business is the system of the taxation. Now there is a number special taxation models for the subjects of small business. In 2012, the new patent system of the taxation was accepted. This system partly replaces a unified tax on imputed income (ENVD), but unlike the latter, it is being applied on a voluntary basis. Terms of statements for transition to the special tax modes are increased, and the declarative system of transition to the special modes is changed on notifying (The tax Code of the Russian Federation (part second) of 05.08.2000 № 177-FZ).

In many respects, these changes have progressive positive effect, but problems of the taxation of small business are not fully solved yet. Stimulation of business activity requires improvement and further development of the special tax modes.

The fourth stage of modernization of the state support system concept - is optimizing the process of its rendering. Now state regulation of small business activity in the sphere of rendering state support is not optimum that many state agencies duplicate the same functions, and separate aspects remain out of maintaining these structures. In this regard, it is necessary to carry out more accurate differentiation of functions and problems of the existing infrastructure of state support of small business. Increase of responsibility of employees of state agencies, control of achievement of objectives will provide increase in system effectiveness of the state support in general.

The final stage of implementation of the new concept - improvement of the mechanism of financial and credit support. The operating mechanism of rendering financial and credit support of small business has a number of essential shortcomings, which reduce efficiency of all system of state support of MT and can be eliminated by improvement of this mechanism (Alikayeva, 2014).

The offered stages of the concept modernization represent a vector of its development. In expanded form, basic provisions of the new concept of system of state support of this sector will take form of the program following below:

\subsection{Providing Favorable Conditions of Development of Business Activity}

\subsubsection{Decrease in administrative barriers, realization of the principle of «one window» when rendering state support.}

Decrease in administrative barriers - is one of the most important problems of the state support system of MSP keeping relevance despite the measures for its elimination taken by the authorities. Activity of the authorities rendering state support to small business is opaque to businesspersons in view of their variety and lack of accurate distribution of functions and tasks between them. In our opinion, realization of this task leads to the need of introduction of «one window» principle for rendering state support. Indirect confirmation of the specified measure efficiency is the positive experience of registration of subjects in tax authorities organized by the similar principle. First of all it will reduce a waiting time for the response of state agencies to the address of businessmen about rendering state support (in the conditions of the parallel appeal to different instances it is impossible to reach), and secondly, will simplify an order of its receiving.

In order to avoid complication of tax authorities ' work and creation of additional difficulties businesspersons can provide possibility of obtaining the status of small, micro or medium-sized enterprise in the same statement for transition to special tax regime. It will allow involving the enterprises in system of rendering state support at a stage of start of economic activity, more precisely to carry out monitoring of activity of the enterprises. However, complexity in the offered procedure represents discrepancy of the criteria allowing applying the special tax modes and, criteria of reference of the enterprises to small and average business. The tax authority has to direct applications to Federal Antimonopoly Service and after obtaining the conclusion of FAS - to make the decision on assignment of the status of the subject of MSP and possibility of application of special tax regime if that was chosen as the applicant. If the addressed person (physical or legal entity) in the past (to the current of 3 calendar years preceding year of the address) illegally received state support as the subject of MSP or violated requirements of the legislation on use of the means received from the state as support of MSP, assignment of the status of the subject of MSP and possibility of application of special tax regime to it, has to be refused. At this FAS has to be taken into account, whether were available before violation by the founder of legal entity or his head.

Furthermore, the principle of «one window» assumes rendering consulting and information support. Often businesspersons are badly informed on opportunities of receiving free consultation from state agencies, which has to 
appear employees of state agencies, including also tax inspectors. In practice, receiving such consultation is almost impossible for a number of reasons. Working load of tax inspectors, as a rule, does not allow finding for each taxpayer time sufficient for an explanation of all-important aspects of their activity. Inspectors are more focused on work with tax disputes and the conflicts, thus working load of them rather high.

Realization of attraction opportunity for rendering free consultations of lawyers, specialists of state agencies demands a long time and sometimes is inaccessible at all. This question is highly topical for small subjects, in particular for micro-subjects of MT as costs of receiving advisory support for them are very considerable. In our opinion, the essential gap in this question consists in absence of development rendering free consultations procedure. The businessperson wishing to begin the business does not address in the MAR first, where the special admission is required, has no information that specialists of the specified ministry will help him. He addresses the one of the tax inspections in the area where the said activity will be carried out. In the presence of the local inspectors and consultants the businessman could receive exhaustive information on a choice organizational right-howl forms, tax regime, special programs of support of the beginning businessmen, existence in this municipality of the rooms represented on favorable terms, etc. By the operating organizations and businesspersons such help, in particular in disputes with IFNS and other situations, will also be in a high demand. Departments of IFNS of work with taxpayers are practically always overloaded and as practice showed, neither opportunities, nor motivation to work with taxpayers, concerning optimization of tax payments, to protection and realization of their rights at them is not present.

Thus, it is necessary to organize workplaces in the territory of the tax inspections for the consultants involved on a competitive basis at the expense of budgetary funds, which would work with the subjects of MT, both new, and already existing. One of alternative versions of solving this problem is involvement of students of older years from higher education institutions of economics and law departments (on a grant basis) under the leadership of representatives the MAR and IFNS. It will allow helping to a wide range of businesspersons without increase in expenses of the budget, and to students - to receive skills and experience, necessary for further work, and perhaps even to find a job.

\subsubsection{Optimization of branch structure of small business}

Support of the start of new subjects of small business and venture small business also first of all consists in weakening the administrative barriers that stimulates creation of bigger number of new small enterprises. Lack of a gain of number of small enterprises at simultaneous increase in their «mortality» also is one of the reasons of stagnation of this sector.

Optimizaing the structure of small business is realized by means of maintenance at the regional level of projects on opening of industrial small enterprises, introduction of innovations; changes of a branch priority (agriculture, etc.) 1996 1997 determined by programs of state support. In view of their discrepancy with priorities of businessmen they didn't bring a notable positive effect and now lost the relevance.

Besides, it is necessary to render state support to those enterprises which financial results of activity, have positive dynamics since investments into unprofitable firms promote only degradation of business and a "Shadowing» of business. Support of start of new subjects of sector of MSP follows from realization of the previous measure of state support.

The consulting help and involvement of subjects of MSP in system of state support already at the initial stage of implementation of activity will allow to provide survival and real functioning of the registered business structures. Other measure motivating creation of new individual entrepreneurs is active promotion in mass media about measures of state support of sector of MSP.

\subsubsection{Investment of the viable enterprises}

Now the structure which was developed in the mid-nineties of the XX-th century, that is a prevalence of branch of trade and the address in the sphere of small enterprises remains. Especially the question for the micro-enterprises is particularly acute. Partially selective support of the enterprises of branches which are priority for the concrete region, carries out this task. So, in KBR the enterprises conducting an innovative, production activity, which are engaged in processing of agricultural production are supported. Practice shows that it isn't enough of it as serious positive shifts in structure of MT of the region don't happen.

In our opinion, providing state support to separate branches breaks equality of subjects of MT. The state shouldn't impose to businessmen kinds of activity which aren't of interest for them, and the businessmen who are engaged in different types of business have to be on an equal footing.

Besides, in parallel with branch accessory turning point at selection of projects is their social importance. So, for 
example, for the state the projects having bigger budgetary (will bring more taxes) and social (it will be more created workplaces) effects, but are more interesting to the businessmen introducing innovations, these indicators can't be defining. And small projects will be inferior a priori to larger in view of scale.

So when providing state support of a measure of its rendering have to be differentiated for different groups of subjects of MSP. For microsubjects indicators of the budgetary efficiency and number of workplaces can't be effective selection criteria.

In our opinion, for the microenterprises the target expenditure of means and viability of the subject have to be the defining criteria. Viability of the subject will be defined by implementation and maintenance of activity of the enterprise.

With increase in dimension of subjects also selection criteria have to become tougher. For group of small enterprises the social effect along with a condition of target use of means and preservations of activity has to be the defining. For medium-sized enterprises the circle of criteria extends, it joins along with above-stated the budgetary effect, economic efficiency, innovation, environmental friendliness (Novoselova \& Novoselov, 2015 \& Novoselova, 2013).

Such selection will allow to improve structure of MSP in favor of really functioning, viable subjects. Improvement of branch structure will be realized through creation of new workplaces, that is branches with higher labor input (production, agriculture) will get advantage at preservation of a principle of equality of all subjects of MSP in rendering state support.

\subsection{Control of Compliance with the Law}

\subsubsection{Antimonopoly regulation}

FAS is insufficiently involved in system of rendering state support of MT now. Possibility of abuses and violations of the competition in the separate local regional markets where quite often a number of the medium-sized or large enterprises put pressure upon the market is a consequence of it, forcing out the small rival enterprises or creating barriers to free occurrence on the market.

The antimonopoly service has to be highly integrated into system of rendering state support of MSP. So, at registration and obtaining the status of the subject of MSP and the right for application of the special tax regime of FAS has to pass the motivated decision on consent or refusal on the statement. Thus assignment of such status has to mean unambiguous possibility of the right of the person for receiving state support as subject of MSP if it has such status. Additional procedures for coordination only promote emergence of corruption of new administrative barriers in development of MSP.

- In order to avoid abuses of subjects of MSP when receiving state support of FAS has to carry out monitoring of activity of MSP in close cooperation with other supervisory authorities. Can be the bases for deprivation of the status of the subject of MSP:

- discrepancy to criteria of reference to MSP sector;

- violation of conditions of rendering state support (inappropriate use of means, non-performance of the accepted obligations);

- fraud.

Procedure of deprivation of the status of MSP and according to a right of use of the state help can happen only in a judicial proceeding.

\subsubsection{Anti-corruption regulation}

Important aspect of rendering state support of MT is anti-corruption regulation. The solution of this task possibly through:

- ensuring transparency of activity of the state agencies which are carrying out support of small business, and the decisions made by them;

- control strengthening, establishment and reduction of deadlines of consideration of addresses of businessmen;

- «joint» making decision on providing investments and guarantees by the state agencies rendering state support of MT;

- the publication in mass media of the concrete directions of an expenditure of budgetary funds for the investment purposes;

- reduction of number of documents at the request for the help of the state and number of allowing procedures.

It will allow to warn quantity of abuses of authority from officials and will increase trust of the population to system of state support. Have to be introduced system of on-line control of a condition of the demand for receiving state support. 
The list of demands and their initiators has to be open and available, number of the demanded documents - limited.

\subsection{Distribution of Responsibility of State Agencies in System of Support of MT}

\subsubsection{Optimization of process of state regulation of MT}

Now state regulation of activity of MT in the sphere of rendering state support isn't optimum that many state agencies duplicate the same functions, and separate aspects remain out of maintaining these structures. In this regard it is necessary to differentiate more accurately both functions, and a task of institutes of the state support of small business. Increase of responsibility of employees of state agencies, control of achievement of objectives will provide increase in system effectiveness of state support in general.

\subsubsection{Decrease in tax pressure on MT, simplification of the account and reporting}

In support of small business also the system of the taxation has to play an important role. Creation of the special modes of the taxation, simplification tax and accounting and the reporting was the most important step in rendering the state support to small business through tax regulation. Despite all shortcomings of these measures (incomplete coverage of taxable base, absence of real data on the amount of production and commodity turnover etc.), their application rendered a considerable positive effect on development of small business.

It should be noted that for the last year many important positive changes in the special tax modes are accepted. So, the Federal law of June 25, 2012 № 94 «About modification of parts the first and second the Tax Code of the Russian Federation and separate acts of the Russian Federation» entered patent system of the taxation. This system partly replaces a unified taxon imputed income (ENVD), but unlike it is applied on a voluntary basis. Terms of statements for transition to the special tax modes (The act of the Russian Federation of 24.07.2007 № 209-FZ) are increased. In many respects these changes have progressive positive character, but problems of the taxation of small business are solved not fully. Now improvement and further development of the special tax modes are necessary, namely:

1) Fixing of concept «subjects of MSP in the Tax Code;

2) Reduction of conditions of application of the special tax modes and conditions of reference of the enterprises to small and to average to the uniform standard, thus advantage has to be behind the formulations fixed in SL209.

3) Entering an ascending scale of a unified tax - from $5 \%$ to $15 \%$ for the simplified tax system. In our opinion, it is necessary to range a rate at the simplified tax system depending on the size of the enterprise. For the microenterprises, the tax rate at object «the income minus expenses» has to make $5 \%$. It is also necessary to keep opportunity for this group of companies of a choice of alternative object of the taxation - «income». However, it is recommended to count a tax on gross revenue (but not from a turn) and to keep a former tax rate $-6 \%$.

For small enterprises, the tax rate has to make from $5 \%$ to $10 \%$, for medium-sized enterprises - from $10 \%$ to $15 \%$ inclusive, but thus they will have no opportunity to choose other object of the taxation («income»). Thus, introduction of obligation of conducting accounting and the reporting (balance and the profit and loss report) is necessary for these two groups of companies. It will allow increasing transparency of activity of small and medium-sized enterprises. Thus expenses on conducting accounting will not increase expenses of businesspersons as more than 15 practically always have the enterprises with number of workers in the staff of one or several accounting workers (The official site of the Ministry of Economic Development of KBR http://economykbr.ru).

The microenterprises have to keep release from conducting accounting and delivery of accounting reports. It will allow keeping expenses of the microenterprises at the former level as the enterprises, which do not have the accounting worker in the staff will be able to continue to keep account according to the simplified scheme that does not demand existence of special knowledge and qualification. Opacity of activity of the microenterprises does not represent serious problems in view of the small scale of the organization;

4) Establishing possibility of acceptance to a deduction of the entrance VAT at the subsequent realization of goods «simplifications» to the VAT organizations payers. That is the organization applying the simplified tax system cannot compensate the tax from the budget paid at acquisition of goods, works, services, as itself is not the payer of a tax independently. At resale of goods, «simplifications» (there are invoices and payment confirmation of the VAT) the buyer payer of the VAT needs to create opportunity to receive compensation from 
the tax sum which is earlier paid on these goods (in the presence of the invoice, exposed by «simplifications», and data of the invoice received at acquisition of these goods by it, and also confirmations of its payment). Such approach will allow to:

- exclude possibility of frauds;

- increase efficiency of interaction of «simplifications» with the enterprises of medium and large business;

- avoid double taxation of the VAT of the same goods.

5) Entering opportunity to hand over the «zero» declaration at application of ENVD.

6) Imposing the concept «conscientious taxpayer» and a ban of carrying out exit checks of such taxpayers micro and small enterprises. In the domestic legislation the concept of «unfair taxpayers» is entered, the criteria allowing to select taxpayers for carrying out exit tax audits are established.

In our opinion, introduction of concept of «conscientious taxpayers», that is the enterprises observing tax discipline, indicators of the income and, respectively, tax assignments, at which above averages, is necessary. It will allow getting certain advantages to «conscientious taxpayers» - subjects of MT: cancellation of carrying out exit checks during the periods when the tax discipline wasn't broken, tax payments and indicators of profitability were higher than the industry average.

\section{Legislative Fixing of the Volumes of Investment into MT from the Budget}

Expenses on the investment purposes often suffer because of redistribution of budgetary funds for other purposes that creates a vicious circle - absence of investments leads to degradation of MT, decrease in their number, and it, in turn, conducts to the unemployment growth, strengthening of social tension in regions.

\section{Information Support}

Training of the population in finance and bases of business is the most priority in stimulation of an enterprise initiative of a general population. Active support by regional and local authorities of educational programs for training in bases of business will allow to create bigger number of economically active people who at creating favorable conditions for development of business will open the new enterprises, to master innovations. Attraction for training of the population of employees of tax administrations, successful businessmen, representatives the MAR and some other civil services will allow to achieve high efficiency of process of training, will increase interest of the population in a business education.

\section{Concluding Remarks}

Absence in mass media of information on the main measures and programs of support of small business in regions, opacity of activity of regional civil services are the main shortcomings of the existing system of state support, and don't allow to judge lack of feedback with subjects of small business efficiency of the taken measures adequately. Often in regions the population is a little informed on the existing privileges and preferences for small business as regional state agencies aren't interested in it. It also generates opportunities for abuses and corruption, reduces trust of the population to the state and system of state regulation of MT in this connection we recommend legislative fixing of these private purposes in the legislation both on regional, and at the federal level. Thus, implementation of the new concept of small business and its purposes will allow to provide a stable sustainable development of small business on macro- and mesolevels.

\section{References}

The tax Code of the Russian Federation (part second) of 05.08.2000 № 177-FZ//Collection of the legislation of the Russian Federation, 07.08.2000, № 32, Art. 3340 .

The act of the Russian Federation of 24.07.2007 № 209-FZ «About development of small and average business in the Russian Federations//Collection of the legislation of the Russian Federation, 30.07.2007, № 31, Art. 4006.

The act of the Russian Federation of 26.07.2006 № 135-FZ «About protection of the competition»//the Russian newspaper, 27.07.2006, № 162.

The law KBR of 24.04.2007 № 29-RZ «About the approval of the republican target program «Development and Support of Small Business in Kabardino-Balkar Republic for 2007 - 2011.»//Kabardino-Balkarian However, 27.04.2007, № 125.

The law KBR of 14.11.2014 № 58-RZ «About modification of article 2 of the Law of Kabardino-Balkar Republic «About a tax rate at use of the simplified system of the taxation in the territory of Kabardino-Balkar Republic»»« 
Alikayeva, M.V. (2014) Modernization of the mechanism of financial and credit support of small business//M.V. Alikayeva, T.A. Nalchadzhi \& M.B. Ksanayev//Economy. Taxes. Right. № 4. pp. 67-72.

Alikayeva, M.V. (2006) Theoretical aspects of development of small business: institutional and evolutionary approach / M.V. Alikayeva \& M.B. Ksanayev//Business. № 6. pp. 78-81.

Vilensky, A.V. (2006) Formirovaniye of an institutional makrosreda of small business of Russia: yew. ... Dr.s econ. sciences: 08.00.05/Alexander Viktorovich Vilensky. M. pp. 364.

Novoselova, N.N. \& Novoselov S.N. (2015) Institutional imperatives and finan-sovo-information tools of development of branch systems//Business in the law. № 2. pp. 229-234.

Novoselova, N.N. (2013) Research of processes of formation, use and the analysis of financial streams in the industry//Business in the law. № 3. pp. 114-117.

The official site of the Ministry of Economic Development of KBR - http://economykbr.ru 